\title{
Green Synthesis of Silver Nanoparticles by Water Soluble Fraction of the Extracellular Polysaccharides/Matrix of the Cyanobacterium Nostoc Commune and its Application as a Potent Fungal Surface Sterilizing Agent of Seed Crops
}

\author{
Fatthy Mohamed Morsy ${ }^{1}$, Nivien Allam Nafady ${ }^{1}$, Mohamed Hemida Abd-Alla ${ }^{1, *}$, Deia Abd Elhady ${ }^{2}$ \\ ${ }^{1}$ Botany and Microbiology Department, Faculty of Science, Assiut University, Assiut, Egypt \\ ${ }^{2}$ Chemistry Department, Faculty of Science, Assiut University, Assiut, Egypt \\ *Corresponding Author: mhabdalla2002@yahoo.com
}

Copyright (C) 2014 Horizon Research Publishing All rights reserved.

\begin{abstract}
Studying of nanoparticle structures is gaining momentum because of their great potential in improving several fields of science such as agriculture. The water soluble fraction of the extracellular polysaccharides (EPS)/matrix of the highly EPS producing cyanobacterium Nostoc commune have been used as a potent reducing and capping agent for green synthesis of silver nanoparticles. The size of these nanoparticles with the EPS coat was found to be in the range of $15-54 \mathrm{~nm}$ as analyzed using transmission electron micrographs. Interestingly, after washing the EPS coated silver nanoparticles by ethanol, the size of nanoparticles reduced to less than $15 \mathrm{~nm}$ due to the formation of silver oxide nanoparticles and removal of the EPS coat. Silver nanoparticles showed antibacterial properties against Escherichia coli. The minimum inhibitory concentration (MIC) was $0.012 \mathrm{mg} / \mathrm{ml}$ while the minimum bactericidal concentration (MBC) was $0.016 \mathrm{mg} / \mathrm{ml}$. The slight difference between the MIC and MBC suggests that such silver nanoparticles act as a potent bactericidal agent against E. coli. Presoaking seeds of crop plants (Sorghum and broad bean) in five-fold MBC of silver nanoparticles $(0.08 \mathrm{mg} / \mathrm{ml})$ did not adversely affect the germination of Vicia faba L. and Sorghum bicolor plants. Concomitantly, such fivefold $\mathrm{MBC}$ concentration of silver nanoparticles was powerful sterilizing agent for seeds and grains against seed/grain-borne microorganisms. The results showed gradual depletion of the total colony forming units (CFU) in seeds and grains sterilized with silver nanoparticles than those sterilized with chlorine. These results suggest that the water soluble fraction of the extracellular polysaccharides (EPS)/matrix of Nostoc commune can be used as a potent reducing and capping agent for green synthesis of silver nanoparticles and that silver nanoparticles can be used as a potent surface sterilizing agent of seed crops against phytopathogenic fungi.
\end{abstract}

Keywords Silver Nanoparticles, Nostoc Commune, Green Synthesis, Sterilizing Agent

\section{Introduction}

Silver nanoparticles have received considerable attention because of their antimicrobial properties (1). For the past few years, various rapid chemical methods have been developed for the synthesis of silver nanoparticles (2). Chemical synthesis of nanoparticles leads to presence of traces of toxic chemical adsorbed on the surface which is undesirable in the medical applications of nanoparticles. Development of reliable and eco-friendly processes for synthesis of metallic nanoparticles is an important step in the field of application of nanotechnology. Green synthesis of silver nanoparticles provides an alternative to chemical and physical methods as it is cost effective, environment friendly and does not involve use of costive chemicals.

Microorganisms like bacteria, fungi, actinomycetes and yeasts have been reported to synthesize silver nanoparticles either intra- or extracellular. The biologically synthesized nanoparticles are highly useful for biomedical applications. Different natural products such as monosaccharides have been used as reducing agents in green synthesis of silver nanoparticles. The polysaccharides are emerging as stabilizing and reducing agents for nanoparticles synthesis (3). Natural polysaccharide such as chitosan (4), heparin (5), gum acacia polymer (6) and gum kondagogu (7), were used in the preparation of silver nanoparticles. Recently, a progress in the biological synthesis approach was shown by demonstrating that the shape of $\mathrm{Ag}$ nanoparticles could be tuned from nanospheres to nanoprisms by controlling the growth kinetics of a silver resistant bacteria Morganella psychrotolerans ( 8). Certain bacteria, fungi have been reported to produce much higher amounts of bioactive compounds, which made microorganisms more suitable for large-scale production of nanoparticles (9). An interesting example of the biosynthesis of nanoparticles using fungi was that the cell-associated biosynthesis of silver using Fusarium oxysporum was demonstrated by Ahmad et al. (10). These nanoparticles were overall quasi-spherical with size range 
between 5 and $15 \mathrm{~nm}$. The small size and the high surface of nanoparticles enhance their interaction with the microbes to carry out a broad range of probable antimicrobial activities. The antimicrobial potential of silver nanoparticles have been examined and found to be effective against many pathogens.

Cyanobacterial polysaccharides are renewable resources representing an important class of polymeric materials with reproducible physico-chemical properties, stable cost and supply. The cosmopolitan resurrectant terrestrial cyanobacterium Nostoc commune (N. commune) forms a visible size of colony in which the cells are surrounded by a biochemically complex extracellular matrix which warrants special emphasis for its role in the tolerance of $\mathrm{N}$. commune to extreme desiccation (11). The bulk of the extracellular matrix of $\mathrm{N}$. commune is the extracellular polysaccharides (EPS), mainly glycan (12-14). EPS in N. commune colonies amount to more than $60 \%$ of the dry weight (15) and are constituted with various sugars including glucose, galactose, xylose and uronic acids (16). Some other components are distributed within the EPS such as water stress protein (17, 18 ), a highly stable and active superoxide dismutase (19), the water soluble mycosporine amino acids (20) and the lipid-soluble UV absorbing pigments, scytonemin (21) and extracellular thermostable beta D-glucosidase and beta galactosidase (22).

This study focuses on the green synthesis of metallic nanoparticles of silver using a reduction of aqueous $\mathrm{Ag}^{+}$ion by the water soluble fraction of the extracellular polysaccharides/matrix of the potent EPS producing cyanobacterium Nostoc commune. The potency of silver nanoparticles as a seed/grain sterilizing agent was also tested with illustrating the effect of silver nanoparticles on germination of two crop plants.

\section{Materials and Methods}

\subsection{Organisms and Culture Conditions}

Naturally growing colonies of Nostoc commune was collected from Kanazawa University Campus in Japan seven years ago (22). This cyanobacterium is one of the resurrecting organisms that retrieve its full biological activity after rewetting the dry colonies even if it was dried for several years. The field collected samples was washed with tape water, air dried and stored at room temperature for later use in experiments.

Preparation of water soluble fraction of extracellular polysaccharides/matrix of cyanobacterium Nostoc commune

Water soluble fraction of the extracellular polysaccharides/matrix of the natural growing colonies of the terrestrial cyanobacterium Nostoc commune were prepared as described by Morsy et al. (22). Dry colonies (10 g) were rehydrated, suspended in $100 \mathrm{ml}$ of $0.75 \mathrm{M}$ potassium phosphate buffer $(\mathrm{pH} 7)$ and homogenized in a blender three times at medium speed for $10 \mathrm{~s}$ each. After stirring overnight at room temperature, the suspension was further homogenized in a blender three times for $10 \mathrm{~s}$ each at medium speed and left to stand for $10 \mathrm{~min}$ at ambient temperature. The upper extracellular polysaccharides layer was removed using a spatula and the lower aqueous layer was centrifuged at $6,000 \mathrm{x}$ g for $10 \mathrm{~min}$ at $20^{\circ} \mathrm{C}$. The pellet containing intact EPS-free cells of Nostoc commune was discarded and the supernatant which retained the water soluble fraction of the EPSs was dialyzed overnight against dist water and freez-dryied using a lyophilizer and stored at $-20{ }^{\circ} \mathrm{C}$ for subsequent experiments.

Bioynthesis of silver nanoparticles by water soluble extracellular polysaccharides/matrix of the cyanobacterium Nostoc commune

Silver nanoparticles were synthesized in $50 \mathrm{~mL}$ of water containing EPS $(10 \mathrm{mg} / \mathrm{mL})$ of the cyanobacterium Nostoc commune and silver nitrate $(30 \mathrm{mM})$. The reaction was autoclaved at $15 \mathrm{psi}$ and $121{ }^{\circ} \mathrm{C}$ for $5 \mathrm{~min}$. Centrifugation was conducted at $15,000 \mathrm{xg}$ for $30 \mathrm{~min}$ at $20{ }^{\circ} \mathrm{C}$ to precipitate silver nanoparticles. After washing the precipitate three times by distilled water in order to clean it from any adsorbed silver ions, the precipitate (silver nanoparticles) was then diluted with a few milliliters of distilled water and stored at room temperature.

\subsection{Measurements for Characterization}

To characterize the silver nanoparticles and their dispersion, drops of $10 \mu \mathrm{L}$ of colloidal silver nanoparticles were placed onto a carbon-film-coated copper grid and allowed to dry for $30 \mathrm{~min}$. After that, the images of the silver nanoparticles were obtained by a JEOL-JEM-2010XII microscope operated at $200 \mathrm{kV}$ with a magnification of up to 500000 times. In addition, the TEM data of the particle shape and size of the silver nanoparticles were analyzed.

The formation of products of silver nanoparticles was investigated by UV-Vis spectrophotometer (Thomson Scientific, model: Evolution 3000). The absorbance of solutions was measured in the wavelength spectra range 285-870 nm, which included the maximum of absorbance of AgNPs. The measurements were carried out immediately after the synthesis procedure and along the duration of this study.

\subsection{Stability of AgNPs}

In order to study the effect of the storage conditions on the AgNPs shape and size, each of the prepared solution was divided into two polypropylene bottles, covered with aluminum foil and stored in the dark at room temperature. Periodical absorbance measurements of the NP solutions were carried out during 90 days.

Bacteriostatic versus bactericidal properties of silver nanoparticles against Escherichia coli

Growth condition of E. coli

E. coli HD701 was maintained aerobically at $30{ }^{\circ} \mathrm{C}$ on 
nutrient agar. Prior to antibacterial experiments, E. coli was grown aerobically overnight on nutrient broth [containing (g $\mathrm{L}^{-1}$ Peptone, 5; beef extract, $\left.5 ; \mathrm{NaCl}, 3\right]$ with shaking $(100$ rpm) at $30^{\circ} \mathrm{C}$.

\subsection{Determination of Minimum Inhibitory Concentration (MIC)}

The concentration of silver nanoparticles in diluted solutions was calculated from a standard curve of the optical density at $415 \mathrm{~nm}$ (maximum absorbance wavelength) versus mass concentration $(\mathrm{mg} / \mathrm{ml})$. The minimum inhibitory concentration (MIC) was determined as the lowest concentration of an antimicrobial (i.e. silver nanoparticles) that inhibit the growth of a microorganism after overnight incubation. A series of nutrient broth were mixed with the serially diluted silver nanoparticles solutions and a standard inoculum of E. coli was applied to give rise a final $\mathrm{OD}_{600} \mathrm{~nm}$ equal 0.02 at the start of cultures. After overnight incubation, the MIC was the first broth in which growth of E. coli has been inhibited by the antibacterial effect of silver nanoparticles.

\subsection{Determination of Minimum Bactericidal Concentration (MBC)}

The minimum bactericidal concentration (MBC) was determined as the lowest concentration of silver nanoparticles required to kill E. coli. It was determined from broth dilution MIC tests by sub-culturing to nutrient agar plates without silver nanoparticles.

Effect of silver nanoparticles on seed germination of crop plants

Vicia faba L. seeds and grains of Sorghum bicolor were treated for $1 \mathrm{~min}$ with fivefold MBC concentration of silver nanoparticles $(0.08 \mathrm{mg} / \mathrm{ml})$. Then they were germinated in dark for 4 days in Petri dishes containing $5 \mathrm{ml}$ of sterile water. Non-treated seeds/grains were germinated at same conditions as a control.

Silver nanoparticles as a sterilizing agent against seed borne fungi

Samples of sorghum, maize, soybean and sesame were collected from different markets at Assiut city, Egypt. To compare between chlorine (Sodium hypochlorite) and biologically synthesized silver nanoparticles (AgNPs) as sterilizing agents, fifty seeds or grains from each sample were surface sterilized in one percent sodium hypochlorite $(\mathrm{NaOCl})$ for $5 \mathrm{~min}$ and another fifty seeds were surface sterilized with AgNPs for $5 \mathrm{~min}$. The occurrence of Fusarium and other fungi on seeds or grains were detected by plating technique. Five seeds or grains from each sample were cultured on the surface of dichloran chloramphenicol peptone agar (DCPA) plates (23). The plates were incubated at $25{ }^{\circ} \mathrm{C}$ for 7 days and the developing fungi were counted, isolated, identified and calculated as colony forming units (CFU) per 50 seeds or grains.

\section{Results and Discussion}

Bioynthesis of silver nanoparticles by the water soluble extracellular polysaccharides/matrix of the cyanobacterium Nostoc commune

The current study focuses on the new synthesis of metallic bionanoparticles of silver using a reduction of aqueous $\mathrm{Ag}^{+}$ ion by water soluble extracellular polysaccharides/matrix of the cyanobacterium Nostoc commune. There are two stages when silver nanoparticles generate in the solution. The first stage is to generate silver nuclei, and the second stage is the growth of silver nanoparticles. So, it is important to control the preparation process that silver nuclei must generate faster and grow up slower, which requires better control of the initial concentration of silver nitrate. The initial concentration of silver salt is changed from 0.5 to $30 \mathrm{mM}$ with $1 \%$ water soluble EPS of Nostoc commune and the reaction was autoclaved at $15 \mathrm{psi}$ and $121^{\circ} \mathrm{C}$ for $5 \mathrm{~min}$. The synthesized nanoparticles had a brown reddish color by sight in aqueous solution. Fig. 1 shows such effect of concentration of silver ions on the UV-Vis spectrum of silver nanoparticles. It is obvious that the absorbance increments with adding more silver ions up to $30 \mathrm{mM}$ at maximum wavelength of about $415 \mathrm{~nm}$.

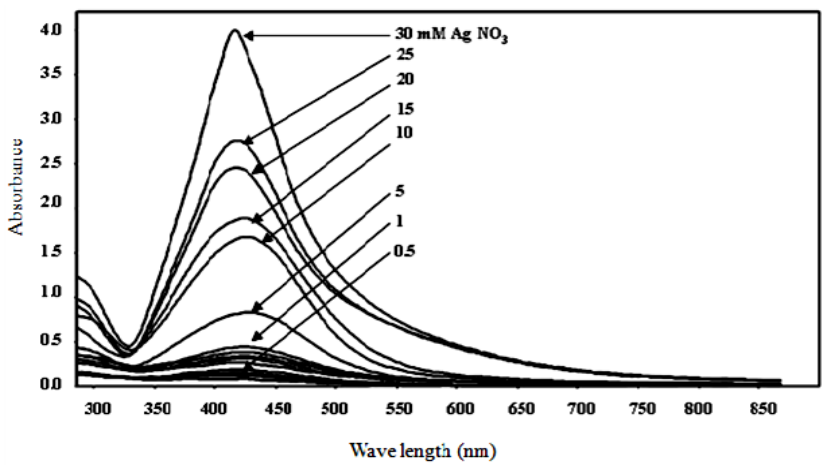

Figure 1. UV-Vis absorption spectrum of silver nanoparticles synthesized by treating various concentrations $(0.5$ to $30 \mathrm{mM})$ aqueous $\mathrm{AgNO}_{3}$ solution with $1 \%$ water soluble EPS of Nostoc commune

The effect of different percentages of reducing agent (water soluble EPS of Nostoc commune) on the intensity of silver nanoparticles preparation were investigated (Fig. 2) at $121^{\circ} \mathrm{C}$. It is shown that the absorbance increased sharply from $0.1 \%$ to $1 \%$ and then decreased up to half by adding $10 \%$ of reducing agent. This result could be due to the retardation of growing silver nanoparticles in the presence of high amount of EPS of Nostoc commune. As well, the depression of absorption might be due to the formation of inter bonding between the functional groups of EPS of Nostoc commune leading to decrease its reducing power. It is concluded from figure 1 and 2 that $30 \mathrm{mM}$ silver nitrate and $1 \%$ EPS of Nostoc commune are optimum for mass scale biosynthesis of silver nanoparticles. 


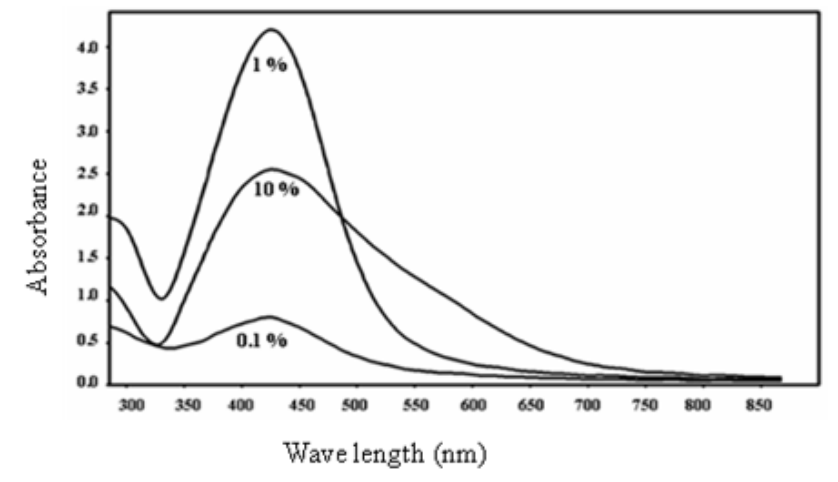

Figure 2. UV-Vis absorption spectrum of silver nanoparticles synthesized by treating $30 \mathrm{mM}$ aqueous $\mathrm{AgNO}_{3}$ solution with various concentrations $(0.1,1$ and $10 \%)$ of water soluble EPS of Nostoc commune

It is a key point to cap effectively the metal nanoparticles. The surface activity of nanoparticles makes reunite and form a larger size group with number of weak interfaces easily. Adding capping agent can prevent the growth of reunion particles and improves the dispersion of particles. At the same time, it can hinder silver nanoparticles from contacting with oxygen and prevent them from being oxidized. In the present study, it is obvious that the silver nanoparticles were strongly coated by EPS of the cyanobacterium Nostoc commune. This was proved by washing these EPS coated silver nanoparticles by ethanol. The color of nanoparticles transformed into gray color indicating the removal of EPS coated layer and oxidation of silver nanoparticles into silver oxide nanoparticles. This result indicates that EPS coating prohibited the silver nanoparticles from contacting with oxygen.

The change of absorbance within the time of silver nanoparticles formation was followed. The foremost change observed in the absorbance spectra was that, after an initial increase of the silver nanoparticles absorbance with time it remained approximately constant. The measured time here in this study has been calculated after finishing the corresponding procedure as described in the experimental section. The constant absorbance is reached after $2 \mathrm{~min}$. As well, it was observed that the stability of absorbance of silver nanoparticles was remained constant within the period of study i.e. 90 days at room temperature. This could be due to the possibility of protein and/or polysaccharides to bind with silver nanoparticles that lead to the stabilization of AgNPs by surface binding force. Intact cyanobacterial cells have been used for biosynthesis of silver nanoparticles $(24,25)$. However the use of intact microbial cells for biosynthesis of silver nanoparticles faces a trouble of separating the formed naoparticles from the microbial cells and cell fractions. The use of the water soluble extracellular polysaccharides (EPS)/matrix of the highly EPS producing cyanobacterium Nostoc commune for preparation of silver nanoparticles, avoids such trouble.

Samples for transmission electron micrographs (TEM) measurements have been prepared by placing a drop of suspension on a copper grid coated with carbon film.
According to the TEM images, the morphology of the silver nanoparticles synthesized by EPS of N. Commune was observed and approximately spherical (Fig. 3A) with average size range $15-45 \mathrm{~nm}$.
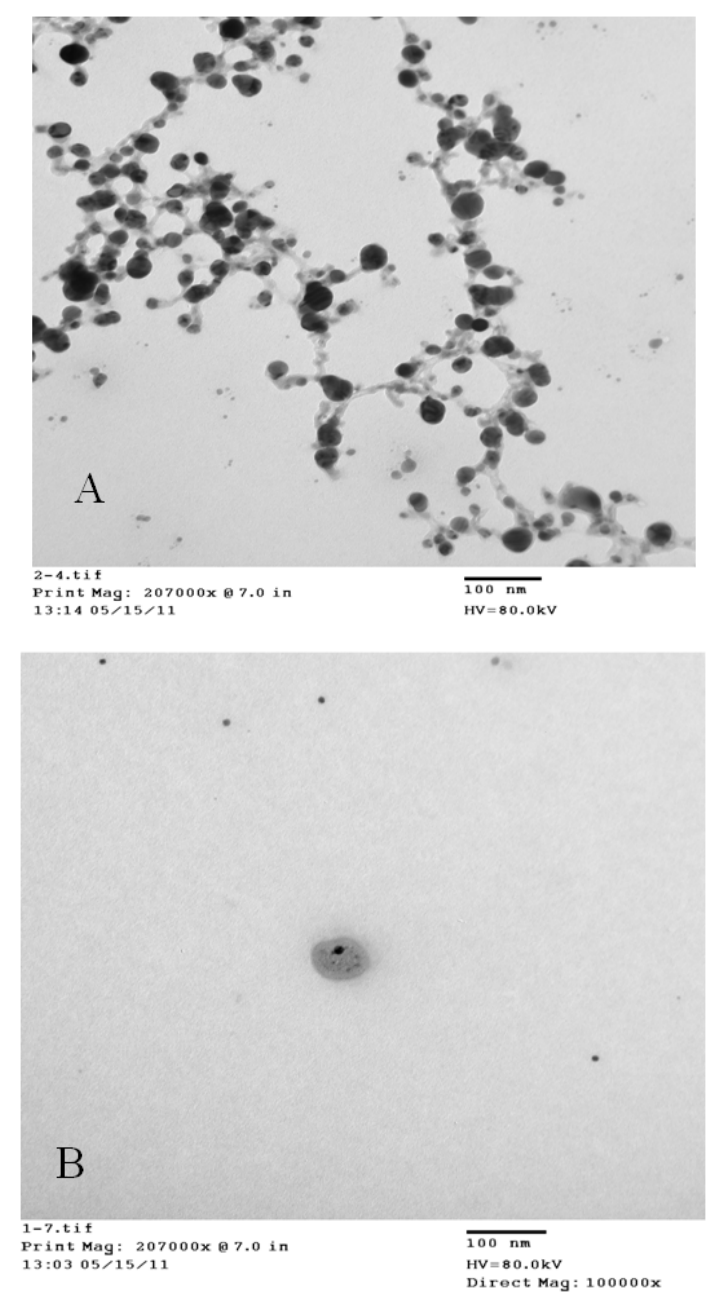

Figure 3. TEM image (A) of AgNPs prepared by $30 \mathrm{mM}$ silver nitrate and $1 \%$ EPS of the cyanobacterium Nostoc commune. TEM image (B) of AgNPs after washing the AgNPs by ethanol

Interestingly, it was observed that the size of silver nanoparticles reduced down to less than $15 \mathrm{~nm}$ after the washing of nanoparticles by ethanol as analyzed using transmission electron micrographs (Fig. 3B). This might probably due to the oxidation of silver nanoparticles into silver oxide nanoparticles with the formation of gray color

\subsection{Bacteriostatic Versus Bactericidal Properties of Silver Nanoparticles against E. Coli}

Silver nanoparticles prepared in this study showed antibacterial properties against Escherichia coli (Fig. 4). The minimum inhibitory concentration (MIC) was $0.012 \mathrm{mg} / \mathrm{ml}$ while the minimum bactericidal concentration (MBC) was $0.016 \mathrm{mg} / \mathrm{ml}$. Antimicrobials are usually regarded as bactericidal if the MBC is no more than four times the MIC (26). The slight difference between the MIC and MBC suggests that such silver nanoparticles act as a potent 
bactericidal agent against E. coli

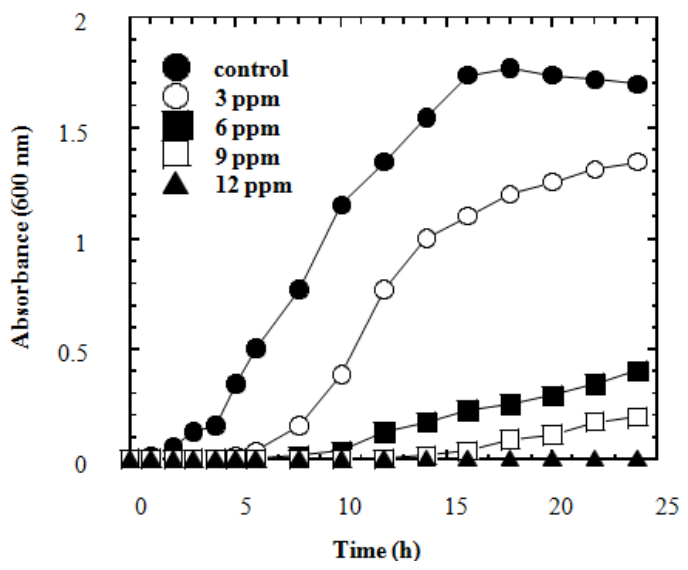

Figure 4. Effect of AgNPs in growth curve of Escherichia coli

\subsection{Effect of Silver Nanoparticles on Seed Germination Of Broad Bean and Sorghum}

Presoaking broad bean seeds and sorghum grains for 1 min in five should MBC of silver nanoparticles did not adversely affect the germination or seedling growth of the investigated higher plants (Fig. 5).

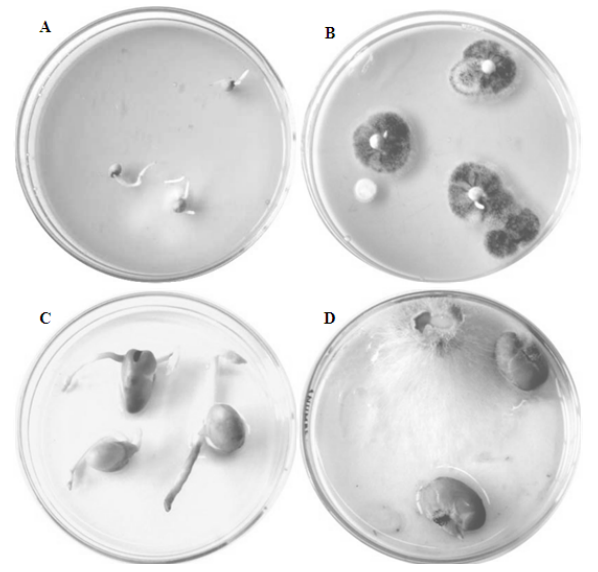

Figure 5. Potency of AgNPs as sterilizing agent against seaborne fungi. Photograph (A) AgNPs treated Sorghum grains; (B) Non-treated (control) Sorghum grains; (C) AgNPs treated broad bean seeds; (D) Non-treated (control) broad bean seeds

Silver nanoparticles are emerging as one of the fastest growing nanomaterials with wide applications. Although, there are some fears of an adverse effect of silver nanoparticles on plants and environment (27), the results presented in this study suggest that silver nanoparticles might not show adverse effects on higher plants upon increasing the industrial applications of silver nanoparticles. Mazumdar and Ahmed (28) observed higher concentrations $(1 \mathrm{mg} / \mathrm{ml})$ of chemically synthesized silver nanoparticles are toxic to the seedlings of Oryza sativa in Hoagland's nutrient solution. The biologically synthesized AgNPs of $30 \mathrm{mg} / \mathrm{ml}$ is an optimum concentration among the selected concentrations to enhance the maximum growth in seedlings of Boswellia ovalifoliolata (29). AgNPs may be generated new pores on seed coat during penetration which may helps to influx the nutrients inside the seed or AgNPs may carry the nutrients along with which may leads to rapid germination and growth rate (29). However, still many researches are required to have a full insight of the adverse effects of silver nanoparticles to human health and their fate in ecological systems.

\subsection{Silver Nanoparticles as a Sterilizing Agent Against Seed or Grain - Borne Fungi}

Results of our present investigation depict AgNPs induced decrease in frequency of fungal population on all the four types of seed and grain samples studied. Table 1 represented the colony forming units (CFU) on the tested samples (sorghum, maize, soybean and sesame) sterilized with AgNPs or NaOCl. Seven Fusarium species and six other genera (9 fungal species) were recovered from tested seeds and grains. A higher number of fungi was observed in maize grains sterilized with $\mathrm{NaOCl}$ and the lower number was observed in sesame seeds sterilized with AgNPs. Fusarium was isolated from all seeds and grains investigated; constituting $47.63 \%$ of total fungi. Its count fluctuated between $1-13 \mathrm{CFU} / 50$ seeds or grains and the highest count was from soybean seeds sterilized with $\mathrm{NaOCl}$.

The gradual depletion of the total colony forming units in samples sterilized with AgNPs is shown in Fig. (6). Complete inhibition of F. nygamai on sorghum grains and soybean seeds is noted with AgNPs sterilization while comprising $17.24 \%$ and $14.63 \%$ of total Fusarium and $7.5 \%$ and $8.7 \%$ of total fungi with $\mathrm{NaOCl}$ sterilization, respectively. There were different responses of different fungi upon exposure to AgNPs or $\mathrm{NaOCl}$.

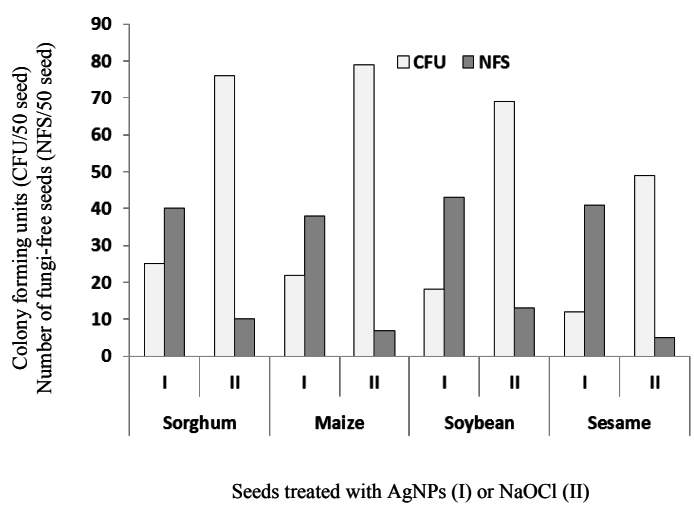

Figure 6. Colony forming units (CFU) and number of fungi-free seeds (NFS) recorded from sorghum, maize, soybean and sesame, surface sterilized with AgNPs (I) or $\mathrm{NaOCl}$ (II) 
Table 1. Seeds or grains-borne fungi of sorghum, maize, soybean and sesame (50 seeds), surface sterilized with AgNPs (I CFU) or NaOCl (II CFU) and cultivated on Dichloran chloramphenicol peptone agar (DCPA) at $25^{\circ} \mathrm{C}$ using direct - plate method

\begin{tabular}{|c|c|c|c|c|c|c|c|c|}
\hline \multirow{3}{*}{ Fungal species } & \multicolumn{8}{|c|}{ Colony forming units (CFU) } \\
\hline & \multicolumn{2}{|c|}{ Sorghum } & \multicolumn{2}{|c|}{ Maize } & \multicolumn{2}{|c|}{ Soybean } & \multicolumn{2}{|c|}{ Sesame } \\
\hline & I & II & I & II & I & II & I & II \\
\hline Fusarium (total) & 6 & 29 & 10 & 39 & 11 & 41 & 5 & 20 \\
\hline F. acutatum & 1 & 4 & 0 & 0 & 0 & 0 & 0 & 0 \\
\hline F. anthophilum & 0 & 0 & 3 & 6 & 2 & 5 & 0 & 0 \\
\hline F. graminearum & 0 & 0 & 2 & 10 & 1 & 4 & 2 & 9 \\
\hline F. nygamai & 0 & 5 & 2 & 8 & 0 & 6 & 1 & 6 \\
\hline F. solani & 2 & 8 & 3 & 12 & 2 & 8 & 2 & 5 \\
\hline F. subglutinans & 0 & 2 & 0 & 0 & 1 & 5 & 0 & 0 \\
\hline F. verticillioides & 3 & 10 & 0 & 3 & 5 & 13 & 0 & 0 \\
\hline Other fungi (total) & 19 & 38 & 12 & 40 & 4 & 28 & 7 & 29 \\
\hline Alternaria alternata & 4 & 6 & 0 & 11 & 0 & 0 & 2 & 5 \\
\hline Aspergillus flavus & 5 & 8 & 2 & 5 & 0 & 5 & 0 & 0 \\
\hline Aspergillus niger & 3 & 8 & 4 & 9 & 2 & 5 & 0 & 0 \\
\hline Aspergillus ochraceus & 0 & 0 & 0 & 0 & 0 & 0 & 3 & 5 \\
\hline Aspergillus terreus & 0 & 0 & 0 & 0 & 2 & 6 & 2 & 4 \\
\hline Cladosporium sp. & 2 & 4 & 1 & 5 & 0 & 0 & 0 & 0 \\
\hline Pencillium spp. & 5 & 10 & 3 & 7 & 0 & 8 & 0 & 6 \\
\hline Rhizopus stolonifer & 0 & 2 & 2 & 3 & 0 & 0 & 0 & 9 \\
\hline Trichothecium roseum & 0 & 0 & 0 & 0 & 0 & 4 & 0 & 0 \\
\hline Gross total & 25 & 76 & 22 & 79 & 18 & 69 & 12 & 49 \\
\hline No. of genera & 5 & 6 & 5 & 6 & 2 & 4 & 3 & 5 \\
\hline
\end{tabular}

In our experiment the biosynthesized silver nanoparticles showed excellent antiseptics and we report the efficacy bacteriogenic metal silver nanoparticles to kill pathogenic seed or grain-borne fungi. Chlorine has broad spectrum antimicrobial activity, but it is reasonable to state that the smaller particles having the larger surface area available for interaction will give more fungicidal effect than the larger particles. The toxicity of AgNPs is mainly due to the free silver ions released by the NPs (30). But antimicrobial properties of ionic silver have long been known, the complexities encountered in various environments combined with the unique properties and behaviors of AgNPs (and nanoparticles in general) complicate estimations of the fate of released AgNPs and their microbial interactions (31). The antimicrobial properties of silver nanoparticles synthesized by EPS of Nostoc commune are in consequence with previous reports of the antimicrobial activities of silver nanoparticles (32). Ingle et al. (33) demonstrated antibacterial activity of silver nanoparticles synthesized from F. acuminatum against human pathogenic bacteria like S. typhi, E. coli, S. epidermidis and multi-drug resistant S. aureus, Similarly, Gade et al. (34) reported antibacterial activity of silver nanoparticles against Gram-positive (S. aureus) and Gram-negative (E. coli) bacteria. Silver nanoparticle prepared by the cyanobacterium Microcoleus sp showed antibacterial activity against several pathogenic bacteria (24).

\section{Conclusions}

In the present study, we report one-pot biogenic fabrication of silver nanoparticles by a rapid and simple procedure using the water soluble fraction of the extracellular polysaccharides/matrix of the cyanobacterium Nostoc commune without extra surfactant, capping agent, and/or template. A slight difference observed between the MIC and MBC of silver nanoparticles against E. coli suggesting that such silver nanoparticles act as a potent bactericidal agent. Surface sterilized maize, sorghum, soybean and sesame with AgNPs showed that silver nanoparticles act as a powerful sterilizing agent for seeds and grains against seed borne fungi. Interestingly, the presoaking of broad bean seeds and Sorghum grains in the fivefold MBC of silver nanoparticles $(0.08 \mathrm{mg} / \mathrm{ml})$ did not adversely affect the germination suggesting that silver nanoparticles might not show adverse effects on higher plants upon increasing the industrial applications of silver nanoparticles.

\section{Acknowledgments}

Sincere thanks to Associate Professor Dr. Toshio Sakamoto ( Division of Life Science, Graduate School of Natural Science and Technology, Kanazawa University, Kakuma, Kanazawa, Ishikawa, 920-1192, Japan) for his 
encouragement for study about the distinctive features and applications of Nostoc commune. Sincere thanks to Professor Dr. L.E. Macaskie and Dr. Mark Redwood (School of Biosciences, University of Birmingham, Edgbaston, Birmingham, UK) for kindly providing E. coli HD701.

\section{REFERENCES}

[1] I. Chopra. The increasing use of silver-based products as antimicrobial agents: a useful development or a cause for concern?, J Antimicrob Chemother 59 (4), 587-590, 2007.

[2] A. Panacek, L. Kvitek, R. Prucek, M. Kolar, R. Vecerova, N. Pizurova, V.K. Sharma, T. Nevecna, R. Zboril. Silver colloid nanoparticles: synthesis, characterization, and their antibacterial activity. J Phys Chem B 110 16248-16253, 2006.

[3] G. Sathiyanarayanana, G.S. Kiranb, J. Selvinc. Synthesis of silver nanoparticles by polysaccharide bioflocculant produced from marine Bacillus subtilis MSBN17. Colloids Surf B 102, 13-20, 2013.

[4] Z. Modrzejewska, M. Dorabialska, R. Zarzycki, A. Wojtasz-Pajakk. The Mechanism of sorption of Ag+ ions on chitosan microgranules: IR and NMR studies. Prog. Chem Applic Chit 14, 49-65, 2009.

[5] M.M. Kemp, A. Kumar, S. Mousa, E. Dyskin, M. Yalcin, P Ajayan, J.R. Linhardt, A.S. Mousa. Gold and silver nanoparticles conjugated with heparin derivative possess anti-angiogenesis properties. Nanotechnology 20: 455104 (7pp), 2009.

[6] Y.M Mohan, K.M. Raju, K. Sambasivudu, S. Singh, B. Sreedhar. Preparation of acacia - stabilized silver nanoparticles: A green approach. J Appl Polym Sci, Vol.106, pp.3375-3381, 2007.

[7] A.J. Kora, R.B. Sashidhar, J. Arunachalam. Gum kondagogu (Cochlospermum gossypium): A template for the green synthesis and stabilization of silver nanoparticles with antibacterial application. Carbohydr Polym 82, 670-679, 2010 .

[8] R. Ramanathan, A.P.O’Mullane, R.Y.Parikh, P.M.Smooker, S.K. Bhargava, V.Bansal. Bacterial kinetics-controlled shape-directed biosynthesis of silver nanoplates using Morganella psychrotolerans. Langmuir, 27, 714-719,2011.

[9] K.B. Narayanan, N.Sakthivel. Biological synthesis of metal nanoparticles by microbes. Adv Colloid Interface Sci 156 , $1-13,2010$.

[10] A. Ahmad, P. Mukherjee, P. Senapati, D. Mandal, M.I.Khan, R.Kumar. (2003) Extracellular biosynthesis of silver nanoparticles using the fungus Fusarium oxysporum. Colloids Surf B 28,313-318, 2003.

[11] Y. Tamaru, Y.Takani, T.Yoshida, T.Sakamoto. Crucial role of extracellular polysaccharides in desiccation and freezing tolerance in the terrestrial cyanobacterium Nostoc commune. Appl Environ Microbiol 71, 7327-7333,2005.

[12] D.R. Hill, A. Peat, M.Potts. Biochemistry and structure of the glycan secreted by desiccation-tolerant Nostoc commune (cyanobacteria). Protoplasma 182,126-148, 1994.

[13] R.F.Helm, Z. HuangZ, D.Edwards, H. Leeson , W.Peery, M.Potts.Structural characterization of the released polysaccharide of desiccation-tolerant Nostoc commune DRH-1. J Bacteriol 182,974-982, 2000

[14] E. Shaw , D.R. Hill, N. Brittain , D.J.Wright, U. Täuber, H. Marand, R.F. Helm, M.Potts. Unusual water flux in the extracellular polysaccharide of the cyanobacterium Nostoc commune. Appl Environ Microbiol 69,5679-5684, 2003

[15] D.R.Hill, T.W. Keenan, R.F.Helm, M. Potts, L.M.Crowe, J.H.Crowe. Extracellular polysaccharide of Nostoc commune (Cyanobacteria) inhibits fusion of membrane vesicles during desiccation. J Appl Phycol 9,237-248. 1997.

[16] S. Kajiyama S, A. Kobayashi A . Chemical and biochemical aspects of desiccation tolerant cyanobacterium Nostoc commune. Cryobiol Cryotechnol 49,37-42, 2003.

[17] S. Scherer S, M.Potts . Novel water-stress protein from a desiccation-tolerant cyanobacterium: purification and partial characterization. J Biol Chem 264,12546-12553, 1989.

[18] D.R. Hill , S.L.Hladun, S. Scherer, M.Potts . Water stress proteins of Nostoc commune (Cyanobacteria) are secreted with UV-A/B-absorbing pigments and associate with 1,4-D-xylanohydrolase activity. J Biol Chem 269,7726-7734, 1994.

[19] B. Shirkey, D.P. Kovarcik , D.J.Wright, G.Wilmouth, T.F. Prickett, R.F.Helm, E.M.Gregory, M.Potts. Active Fe-containing superoxide dismutase and abundant sodF mRNA in Nostoc commune (Cyanobacteria) after years of desiccation. J Bacteriol 182,189-197, 2000.

[20] M.Ehling-Schulz , W. Bilger, S. Scherer . UV-B-induced synthesis of photoprotective pigments and extracellular polysaccharides in the terrestrial cyanobacterium Nostoc commune . J Bacteriol 179,1940-1945,1997.

[21] S. W.Hunsucker, B.A.Tissue, M. Potts, R.F.Helm. Screening protocol for the ultraviolet-photoprotective pigment scytonemin. Anal Biochem 288, 227-230, 2001.

[22] F.M.Morsy, S.Kuzuha, Y.Takani, T. Sakamoto . (2008) Novel thermostable glycosidases in the extracellular matrix of the terrestrail cyanobacterium Nostoc commune. J Gen Appl Microbiol 54,243-252. 2008.

[23] S.Andrews, J.I.Pitt . Selective medium for isolation of Fusarium species and dematiaceous Hyphomycetes from cereals. Microbiology, 1235-1238, 1986.

[24] S. S. Sudha, K. Rajamanickam, J. Rengaramanujam. Microalgae mediated synthesis of silver nanoparticles and their antibacterial activity against pathogenic bacteria. Indian J Exp Biol 51, 393-399, 2013

[25] M. F. Lengke, M. E. Fleet, and G. Southam. Biosynthesis of silver nanoparticles by filamentous cyanobacteria from a silver(I) nitrate complex. Langmuir, 23 (5), 2694-2699, 2007.

[26] G. L.French . Bactericidal agents in the treatment of MRSA infections--the potential role of daptomycin. J. Antimicrob Chemother 58 ,1107-17, 2006.

[27] C.Marambio-Jones,E. M.V. Hoek . A review of the antibacterial effects of silver nanomaterials and potential implications for human health and the environment. J 
Nanopart Res 12, 1531-1551, 2010.

[28] H. Mazumdar, G.V. Ahmed. Phytotoxicity effect of silver nanoparticles on Oryza sativa. Int J Chem Tech Res 3, 1494-1500, 2011.

[29] N.Savithramma, S. Ankanna , G. Bhumi . Effect of nanoparticles on seed germination and seedling growth of Boswellia Ovalifoliolata - an endemic and endangered medicinal tree taxon. Nano Vision 2, 61-68, 2012.

[30] E. Navarro, F. Piccapietra, B. Wagner, F. Marconi, R. Kaegi, N. Odzak, L. Sigg, R.Behra . Toxicity of silver nanoparticles to Chlamydomonas renhardtii. Environ Sci Technol 42,8959-8964, 2008

[31] N.Wigginton, A. De Titta, F. Piccapietra, J. Dobias , V. Nesatyy, M. Suter, R. Bernier-Latmani .Binding of silver nanoparticles to bacterial proteins depends on surface modifications and inhibits enzymatic activity. Environ Sci Technol 44,2163-2168, 2010.

[32] V.K.Sharma , R.A.Yngard, Y.Lin. Silver nanoparticles: Green synthesis and their antimicrobial activities. Adv Colloid Interface Sci 145, 83-96, 2009.

[33] A.Ingle , A.Gade, S. Pierrat, C. Sonnichsen , M. Rai . Mycosynthesis of silver nanoparticles using the fungus Fusarium acuminatum and its activity against some human pathogenic bacteria. Curr Nano 4,141-44, 2008.

[34] A. K. Gade, P. Bonde, A. P. Ingle, P.D. Marcato, N. Duran,M. K. Rai . Exploitation of Aspergillus niger for synthesis of silver nanoparticles. J Biobased Mater Bioener 2:243-247, 2008. 